\title{
Slow Breathing Training Reduces Resting Blood Pressure and the Pressure Responses to Exercise
}

\author{
C. U. JONES ${ }^{1}$, B. SANGTHONG ${ }^{1,3}$, O. PACHIRAT ${ }^{2}$, D. A. JONES ${ }^{4}$ \\ ${ }^{1}$ School of Physical Therapy and ${ }^{2}$ Department of Medicine, Khon Kaen University, Thailand, \\ ${ }^{3}$ Faculty of Physical Therapy, Rangsit University, Thailand, ${ }^{4}$ School of Health Care Science, \\ Manchester Metropolitan University, UK
}

Received October 29, 2014

Accepted January 7, 2015

On-line March 24, 2015

\section{Summary}

Slow breathing training reduces resting blood pressure, probably by modifying central autonomic control, but evidence for this is lacking. The pressor response to static handgrip exercise is a measure of autonomic control and the aim of this study was to determine whether slow breathing training modulates the pressor responses to exercise of untrained muscles. Twenty hypertensive patients trained for 8 weeks, 10 with unloaded slow breathing (Unloaded) and 10 breathing against an inspiratory load of $20 \mathrm{~cm}$ $\mathrm{H}_{2} \mathrm{O}$ (Loaded). Ten subjects were untrained controls. Subjects performed a 2 min handgrip pressor test (30\% MVC) pre- and post-training, and blood pressure and heart rate (HR) were measured before the contraction, at the end and following $2 \mathrm{~min}$ recovery. Resting systolic (SBP) and HR were reduced as a result of training, as reported previously. After training there was both a smaller pressor response to hand grip exercise and a more rapid recovery of SBP and HR compared to pre-training. There were no changes in the Controls and no differences between the Unloaded and Loaded groups. Combining the two training groups, the SBP response to handgrip exercise after training was reduced by $10 \mathrm{~mm} \mathrm{Hg}(95 \% \mathrm{CI}:-7,-13)$ and HR by $5 \mathrm{bpm}$ (95\% CI: $-4,-6)$, all $p<0.05$. These results are consistent with slow breathing training modifying central mechanisms regulating cardiovascular function.

\section{Key words}

Hypertension • Slow breathing training • Muscle pressor response - Heart rate variability

\section{Corresponding author}

C. Jones, School of Physical Therapy, Faculty of Associated Medical Science, Khon Kaen University, Mitraparb Road, Khon
Kaen 40002, Thailand. Fax: 006643202085. E-mail: joneschulee@gmail.com

\section{Introduction}

With a prevalence rising to over $60 \%$ in older age groups, hypertension is recognised as a major health problem throughout the world leading to a range of life threatening cardiovascular diseases. While there is a range of pharmaceutical treatments available there is also a need for non-pharmaceutical interventions, partly because they are more affordable in the developing world, but also because they offer the prospect of addressing the underlying problem rather than just the symptoms.

Whole body exercise training has an important role to play in the management of hypertension (Halbert et al. 1997, Whelton et al. 2002) but while the mechanism underlying the improvement are not fully understood there are reasons to think that it involves changes in central autonomic control of blood pressure rather than, or in addition to, any peripheral modifications. For instance, training two legs reduces resting blood pressure (Devereux et al. 2010) and might be analogues to whole body exercise, but the same benefit can be achieved by training only one leg (Ray 1999) or even a relatively small muscle mass such as with hand grip exercise (Ray and Carrasco 2000, Taylor et al. 2003), the latter differing qualitatively and quantitatively from whole body aerobic exercise.

Interestingly, reductions in resting blood pressure comparable with those obtained by whole body exercise are also seen with the practice of yoga and 
meditation (Patel and North 1975, Spicuzza et al. 2000) and a common feature of these techniques is slow and regular breathing (Bernardi et al. 2001b, Cysarz and Büssing 2005). Furthermore, a number of randomized controlled studies have shown slow breathing to be effective in reducing blood pressure (Jones et al. 2010, Schein et al. 2009, 2001, Sharma et al. 2011).

Slow breathing does not place any serious energetic demands to the inspiratory muscles, at least in the absence of an inspiratory load, and is unlikely, therefore, to result in any peripheral adaptations that may occur with aerobic training. An alternative mechanism is that slow breathing training modifies some aspect of the central control of blood pressure. Lehrer et al. (2006, 2003) have shown that heart rate variability (HRV) feedback, which is essentially slow breathing training, increased baroreflex gain.

In addition to increased resting blood pressure, hypertensive subjects have an enhanced blood pressure response to static exercise (Delaney et al. 2010, Sausen et al. 2009). Aerobic training reduces the rise in blood pressure in response to muscle contraction (O'Sullivan and Bell 2001) which may be partly due to metabolic adaptations in the trained muscle (Fisher and White 2004) but it is also possible that there is a down regulation of metaboreflex sensitivity either at the peripheral receptors or of the central autonomic response to afferent stimulation.

It is not known whether slow breathing training which reduces resting blood pressure also reduces the pressor response to muscle contraction, but if it does this would be strong evidence of a central adaptation since slow breathing is most unlikely to cause any adaptations in an untrained peripheral muscle. The primary objective of the present study was, therefore, to examine this point. It was hypothesized that slow breathing training would not only improve resting blood pressure in patients with essential hypertension but would also reduce the blood pressure responses to contraction of a muscle that had not been trained. Although slow breathing entails minimal energy expenditure it is possible that signals modifying autonomic function might arise from working muscles in which case adding an inspiratory load might increase the beneficial effects of slow breathing training.

\section{Methods}

\section{Subject characteristics}

Subjects were recruited from patients attending the hypertension clinic of Srinagarind Hospital into the study that was approved by the Ethical Committee of Khon Kaen University. The patients all received full information about the nature of the study before providing written consent. Inclusion criteria were: essential hypertension, stage I-II, based on recommendations of JNC-VII (Chobanian et al. 2003), aged 35-65 years and of an independent lifestyle. Exclusion criteria were: blood pressure greater 180/110 $\mathrm{mm} \mathrm{Hg}$ or secondary hypertension, respiratory disease, diabetes mellitus, heart, renal or cerebrovascular disease, dyslipidemia or pregnancy within the last 6 months. The subjects' blood pressures were well controlled with enalapril, atenolol or hydrochlorothiazide which they had been receiving for approximately five years and their treatment was continued unchanged for the duration of the study (10 weeks). Following an initial assessment the subjects were randomly assigned to Control and two training groups, Load and No Load. Thirty subjects completed the study; see the previous report (Jones et al. 2010) for further details of the training protocols. The patients' age, physical characteristics, history of hypertension, medication and initial resting blood pressure and heart rate are summarized in Table 1.

\section{Laboratory-based measurements}

Subjects reported to the laboratory between 9-10 am and rested in a comfortable chair for $15 \mathrm{~min}$ before any measurements were made.

\section{Heart rate and heart rate variability}

ECG was recorded with a three lead BIOPAC MP100 system and resting heart rate calculated from the $\mathrm{R}-\mathrm{R}$ interval. Heart rate was then recorded over a $5 \mathrm{~min}$ period with the subjects resting and breathing at 10 12 breaths per minute and subsequently analysed off line for heart rate variability (HRV) in the frequency domain. Total spectral power $\left(\mathrm{ms}^{2}\right)$ and the power in the low frequency $(0.04-0.15 \mathrm{~Hz})$ and high frequency $(0.15-$ $0.4 \mathrm{~Hz}$ ) regions are reported together with the low to high frequency ratio $(\mathrm{LF} / \mathrm{HF})$.

\section{Isometric handgrip challenge}

The challenge consisted of a sustained isometric handgrip contraction on the dominant side with the forearm supported and elbow flexed at 90 degrees. After determining the maximal voluntary contraction (MVC) as the best of three contractions, each separated by two minutes, the subject rested for approximately $30 \mathrm{~min}$ before being given a target of $30 \% \mathrm{MVC}$ to maintain for two minutes with visual feedback. Subjects were 
instructed to breathe normally during the exercise and not to hold their breath. Blood pressure and heart rate were measured on the non-dominant side before the start of the handgrip contraction, in the last $30 \mathrm{~s}$ of the two minute handgrip exercise and again after two minutes of recovery. Blood pressure was measured with an automatic digital bedside monitor (Nikon Kohden-life scope () .

Table 1. Patient characteristics at the start of the study.

\begin{tabular}{|c|c|c|c|}
\hline & $\begin{array}{c}\text { Control } \\
\text { Mean } \pm \text { SD }\end{array}$ & $\begin{array}{c}\text { No load training } \\
\text { Mean } \pm \text { SD }\end{array}$ & $\begin{array}{c}\text { Loaded training } \\
\text { Mean } \pm \text { SD }\end{array}$ \\
\hline Age (years) & $50.4 \pm 5.4$ & $53.4 \pm 4.3$ & $51.4 \pm 5.3$ \\
\hline Weight (kg) & $63.2 \pm 6.5$ & $68.2 \pm 11.7$ & $75.9 \pm 11.0$ \\
\hline Height $(\mathrm{cm})$ & $156.1 \pm 5.2$ & $157.8 \pm 9.7$ & $162.8 \pm 5.1$ \\
\hline$B M I\left(k g . m^{-2}\right)$ & $27.2 \pm 2.1$ & $27.3 \pm 4.7$ & $29.0 \pm 4.6$ \\
\hline Duration (years) & $5.6 \pm 2.5$ & $5.8 \pm 3.4$ & $5.7 \pm 2.3$ \\
\hline Treatment (years) & $4.7 \pm 1.6$ & $5.1 \pm 2.8$ & $4.9 \pm 1.7$ \\
\hline $\mathrm{SBP}(\mathrm{mm} \mathrm{Hg})$ & $131.0 \pm 9.1$ & $135.9 \pm 12.6$ & $137.0 \pm 12.7$ \\
\hline$D B P(m m ~ H g)$ & $77.7 \pm 6.5$ & $79.9 \pm 5.5$ & $81.2 \pm 8.8$ \\
\hline$P P(m m ~ H g)$ & $53.3 \pm 9.4$ & $56.0 \pm 13.7$ & $58.5 \pm 14.2$ \\
\hline$M A P(m m ~ H g)$ & $95.3 \pm 6.0$ & $98.6 \pm 5.5$ & $100.7 \pm 7.9$ \\
\hline$H R(b p m)$ & $75.2 \pm 9.6$ & $73.2 \pm 7.3$ & $76.0 \pm 4.2$ \\
\hline
\end{tabular}

Data for the three patient groups, Control, those undertaking No load training and Loaded training. BMI, body mass index; Duration is the length of time since first diagnosis of hypertension; Treatment is the time since the start of pharmacological treatment; SBP, systolic blood pressure; DBP, diastolic blood pressure; PP, pulse pressure; MAP mean arterial blood pressure; HR, resting heart rate

\section{Slow breathing training protocol}

Subjects inspired deeply using a device that humidified the inspired air. Subjects in the Load group had an inspiratory load of $20 \mathrm{~cm} \mathrm{H}_{2} \mathrm{O}$ while the sham, or No Load group had no additional load (see Jones et al. 2010, for details). Subjects were trained to adopt a breathing pattern with a duty cycle (inspiratory time: total respiratory time) of 0.4 with a total respiratory time of $10 \mathrm{~s}$. The paced breathing was practiced using a metronome in the laboratory until it could be performed reliably without the metronome. Subjects rested for $5 \mathrm{~s}$ after every 6 deep breaths. The training program was performed at home for $30 \mathrm{~min}$, twice a day, and every day for 8 weeks. Control subjects were asked to continue their normal patterns of daily living.

\section{Data analysis and statistics}

Changes in blood pressure and heart rate from pre- to post- training for the three groups, Control, No load and Load, were examined with a 3-way repeated measures ANOVA with as within factors, time (3 levels; baseline, isometric and recovery) and training (pre vs. post), and between factor, type of training (control, unloaded and loaded). HRV data were examined with a 2-way repeated measures ANOVA with as within factors training (pre vs. post), and between factor type of training (control, unloaded and loaded). Where there was evidence of an interaction $(\mathrm{p} \leq 0.05)$ post hoc paired and independent Bonferroni-corrected Student's t tests were used to identify the significant changes as a result of training within and between groups.

\section{Results}

The consequences of slow breathing training for resting blood pressure have been reported previously (Jones et al. 2010) and we present here the heart rate and pressor responses to handgrip exercise, before and after training in Figures 1-3. The previous report was of changes in resting blood pressure measured at home and in the laboratory, in both cases early in the morning. The pressor responses were measured later in the day at the laboratory and the resting blood pressures reported here are the values obtained just before the handgrip exercise. Thus, the resting values reported here are similar, but not identical, to the data in our previous report.

Resting systolic blood pressure and heart rates before and after training are shown in Figures 1-3 (left 
panel, "Rest"). There were significant group interactions for changes in systolic pressure and heart rate with post hoc analysis revealing significant reductions for the two training groups although there were no differences between No load and Loaded. With diastolic pressure the two training groups showed reductions that were greater than seen with the Control group, but there were no significant group interactions. Combining the two training groups, the decrease in resting mean arterial
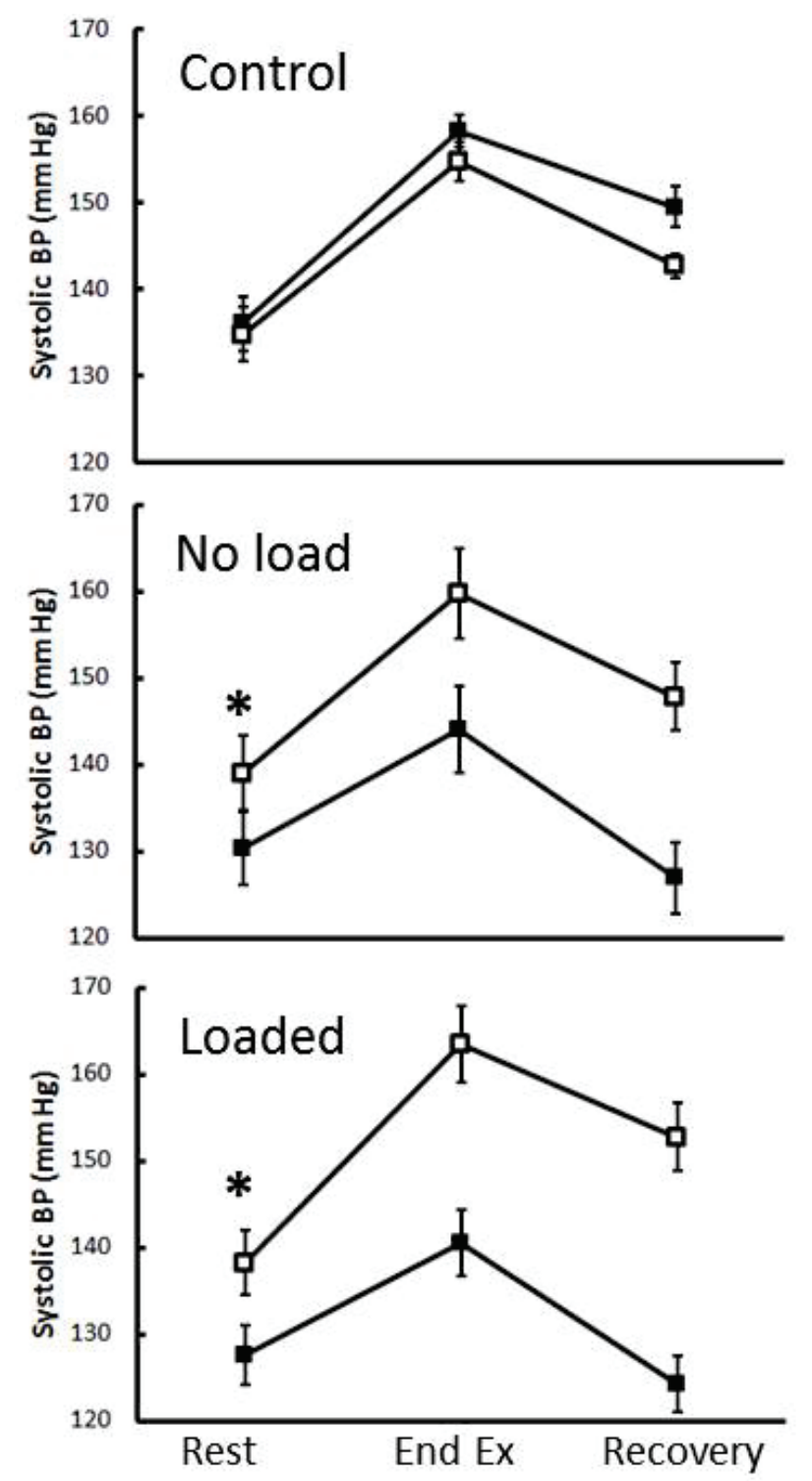

pressure was $10 \mathrm{~mm} \mathrm{Hg}$ (95\% CI: -7, -13). There was a tendency for patients with higher initial resting systolic pressure to show greater decreases with training but this did not achieve statistical significance $(\mathrm{p}=0.14)$.

\section{Pressor response to isometric handgrip}

The effects of the slow breathing training were to reduce the rise in blood pressure and heart rate during the handgrip exercise and to hasten recovery.
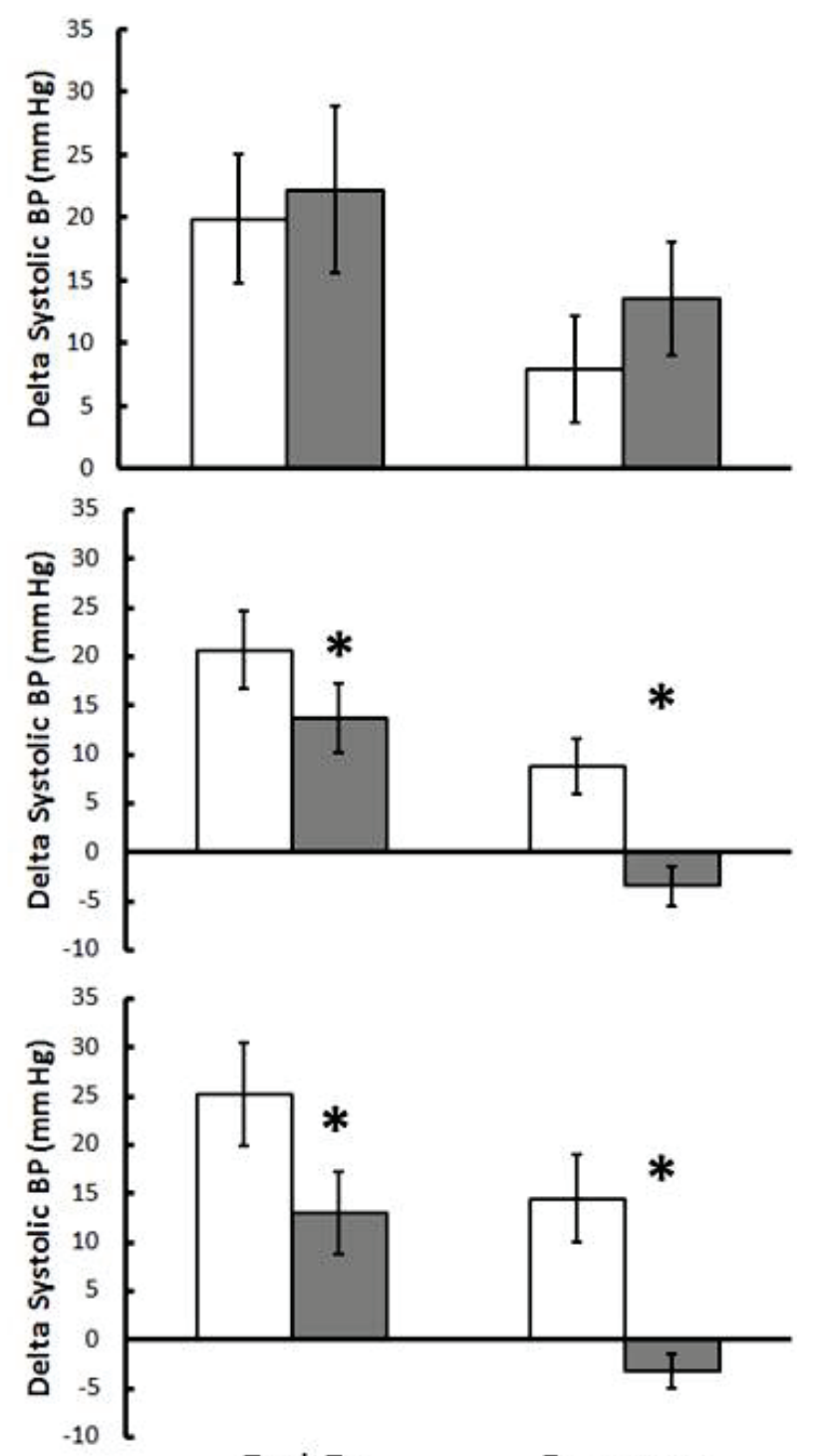

End Ex

\section{Recovery}

Fig. 1. Slow breathing training and systolic blood pressure (sBP). On the left are values for sBP before (open symbols) and after (filled symbols) eight weeks of slow breathing training. Values are mean and standard errors for resting pressure (Rest), after 2 min handgrip contraction (Contract) and after a further 2 min recovery (Recovery). There were three groups, Control, who did no training, No load, who undertook slow breathing but with no load, and Loaded who trained with an inspiratory load. * indicates significant differences between pre- and post-training resting pressures. On the right are the mean changes, with $95 \% \mathrm{CI}$, of sBP from the resting baseline values at the end of the hand grip exercise (End Ex) and subsequent recovery (Recovery) before (open columns) and after (filled columns) training. * indicates significant differences between pre- and post-training; see text for $\mathrm{p}$ values. 


\section{Systolic blood pressure}

Systolic blood pressures for the three groups of subjects, before, at the end of the 2 min handgrip test and following 2 min recovery are shown in Figure 1 (left panel) with the changes from the resting value in the right panel of Figure 1. For the changes from rest at the end of 2 min handgrip there were significant group interactions $(p=0.017)$ and post hoc tests revealed differences between pre- and post-training measurements for the No load $(p=0.002)$ and the Loaded groups $(p<0.001)$ while there were no significant changes in the Control group, nor any differences between the two training groups. Systolic blood pressure fell in the 2 min recovery phase. There were group interactions $(\mathrm{p}<0.001)$ and post hoc tests revealed significant differences between pre- and posttraining measurements for the No Load $(p<0.001)$ and the Loaded group $(\mathrm{p}<0.001)$ while there were no significant changes in the Control group, nor any differences between the two training groups.
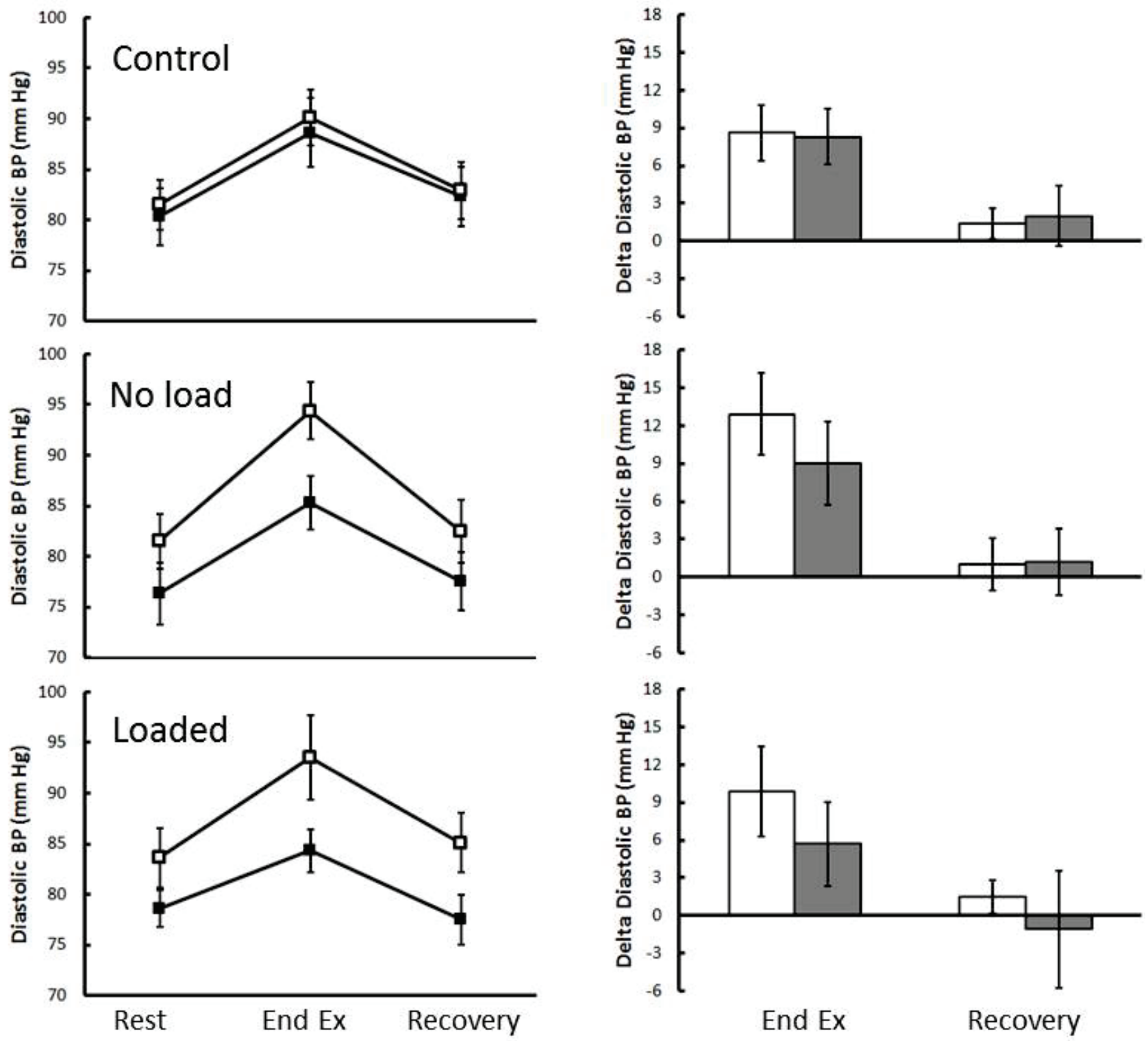

Fig. 2. Slow breathing training and diastolic blood pressure (dBP). On the left are values for dBP before (open symbols) and after (filled symbols) eight weeks of slow breathing training. Values are mean and standard errors for resting pressure (Rest), after 2 min handgrip contraction (Contract) and after a further 2 min recovery (Recovery). There were three groups, Control, who did no training, No load, who undertook slow breathing but with no load, and Loaded who trained with an inspiratory load. On the right are the mean changes, with $95 \% \mathrm{CI}$, of dBP from the resting baseline values during the hand grip test (Contract) and subsequent recovery (Recovery) before (open columns) and after (filled columns) training. 


\section{Diastolic blood pressure}

The diastolic blood pressures before, at the end of the 2 min handgrip test and following 2 min recovery are shown in Figure 2 (left panel) with the changes from resting values in the right panel. There were no significant group interactions either for diastolic pressure responses at end of exercise $(\mathrm{p}=0.371)$ or recovery $(\mathrm{p}=0.431)$ although the data shown in Figure 2 suggest a trend towards a smaller diastolic pressor response after training.

The changes in mean arterial pressure at the end of 2 min handgrip exercise for the combined training groups was $15 \mathrm{~mm} \mathrm{Hg}$ before, and $9 \mathrm{~mm} \mathrm{Hg}$ after eight weeks of training. For the Control group over the same period the comparable values were $12 \mathrm{~mm} \mathrm{Hg}$ and $13 \mathrm{~mm} \mathrm{Hg}$.
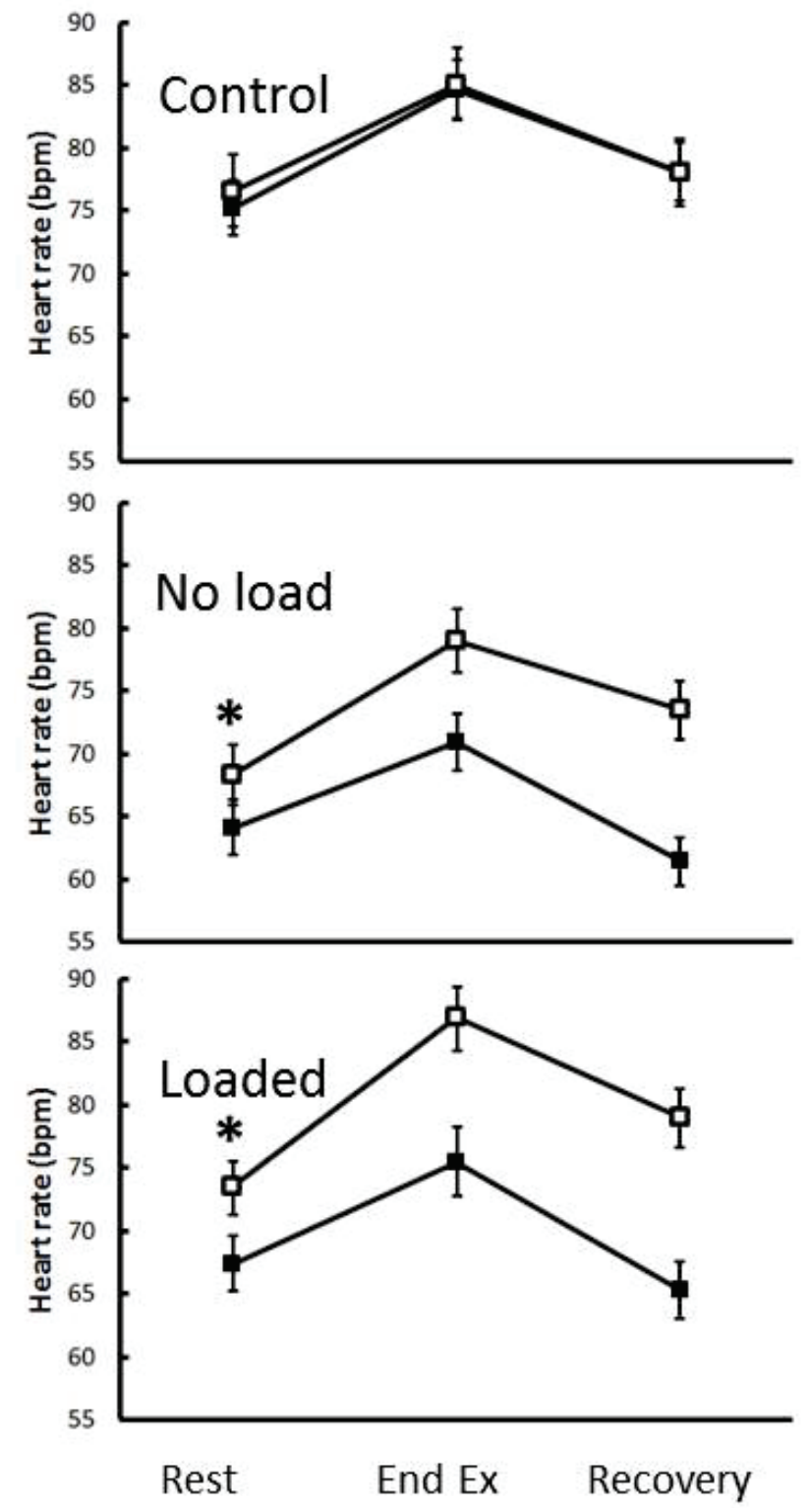
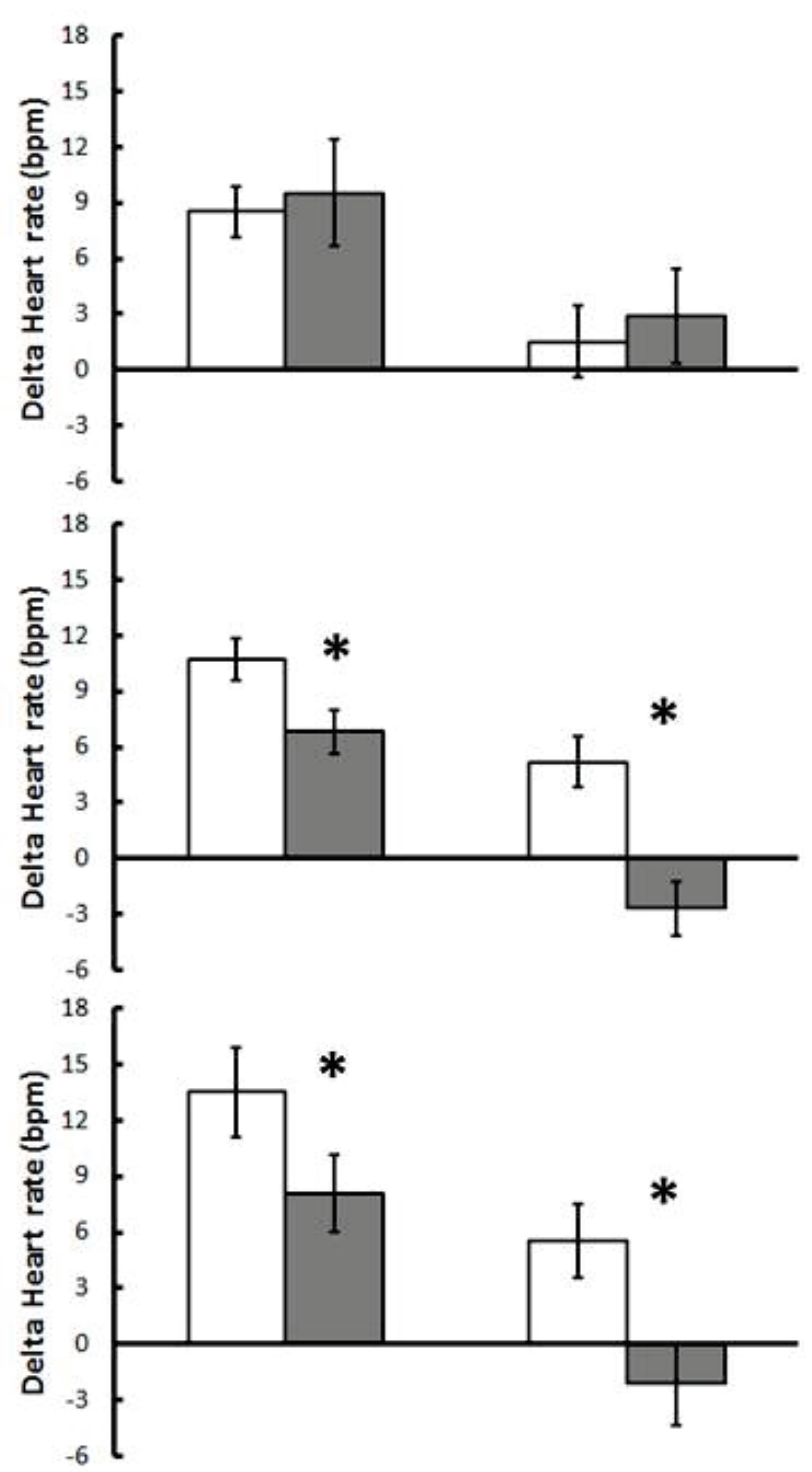

End Ex

\section{Recovery}

Fig. 3. Slow breathing training and heart rate (HR). On the left are values for HR before (open symbols) and after (filled symbols) eight weeks of slow breathing training. Values are for mean resting rates and standard errors (Rest), after 2 min handgrip contraction (Contract) and after a further $2 \mathrm{~min}$ recovery (Recovery). There were three groups, Control, who did no training, No load, who undertook slow breathing but with no load, and Loaded who trained with an inspiratory load. * indicates significant differences between pre- and post-training resting pressures. On the right are the mean changes, with $95 \% \mathrm{CI}$, of HR from the resting baseline values during the hand grip test (Contract) and subsequent recovery (Recovery) before (open columns) and after (filled columns) training. $*$ indicates significant differences between pre- and post-training; see text for $\mathrm{p}$ values. 
Table 2. Heart rate variability pre- and post-training.

\begin{tabular}{|c|c|c|c|c|c|c|c|c|c|}
\hline & & \multicolumn{2}{|c|}{ Total Power $\left(\mathrm{ms}^{2}\right)$} & \multicolumn{2}{|c|}{$\operatorname{LF}\left(\mathrm{ms}^{2}\right)$} & \multicolumn{2}{|c|}{ HF $\left(\mathrm{ms}^{2}\right)$} & \multicolumn{2}{|c|}{$\mathbf{L F} / \mathrm{HF}$} \\
\hline & & Pre & Post & Pre & Post & Pre & Post & Pre & Post \\
\hline \multirow[t]{3}{*}{ Control } & Mean & 506 & 515 & 237 & 285 & 112 & 96 & 2.11 & 3.01 \\
\hline & $\pm S D$ & \pm 108 & \pm 70 & \pm 46 & \pm 40 & \pm 17 & \pm 20 & \pm 0.31 & \pm 0.31 \\
\hline & $p$ & & ns & & $<0.001$ & & $<0.001$ & & $<0.001$ \\
\hline \multirow[t]{3}{*}{ No Load } & Mean & 609 & 654 & 198 & 161 & 245 & 281 & 0.81 & 0.57 \\
\hline & $\pm S D$ & \pm 80 & \pm 78 & \pm 39 & \pm 35 & \pm 43 & \pm 34 & \pm 0.08 & \pm 0.09 \\
\hline & $p$ & & ns & & $<0.001$ & & $<0.001$ & & $<0.001$ \\
\hline \multirow[t]{3}{*}{ Load } & Mean & 688 & 731 & 318 & 271 & 194 & 223 & 1.64 & 1.21 \\
\hline & $\pm S D$ & \pm 103 & \pm 93 & \pm 55 & \pm 58 & \pm 30 & \pm 37 & \pm 0.15 & \pm 0.15 \\
\hline & $p$ & & ns & & $<0.001$ & & $<0.001$ & & $<0.001$ \\
\hline
\end{tabular}

Total spectral power and the power in the low frequency (LF) and high frequency (HF) regions of the spectrum, together with the ratio of power in these two regions (LF/HF). Data are given as mean \pm SD. There were no significant differences in total power but the changes in distribution of power within the spectra were all significant $p<0.001$.

\section{Heart rate}

Values for heart rate before, at the end of the 2 min handgrip test and following 2 min recovery are shown in Figure 3 (left panel) with the changes from resting in the right panel. For the changes from rest after 2 min handgrip exercise there were significant group interactions $(p=0.006)$ and post hoc tests revealed significant differences between values before and after training for the No Load $(\mathrm{p}<0.001)$ and the Loaded group $(\mathrm{p}<0.001)$ while there were no significant changes in the Control group, nor any differences between the two training groups.

\section{Heart rate variability}

Breathing frequency was not specifically regulated but was observed to be between 10-12 breaths per minute during the five minute rest period when heart rate data were collected. There were no group interactions with respect to total spectral power $(\mathrm{p}=0.78)$ but there were highly significant interactions for both high and low frequency power as well as the LF/HF ratio $(p<0.001$ in each case). HRV data are shown in Table 2 and after eight weeks there was a significant shift in the distribution of spectral power from the low to high frequency region in the two training groups $(\mathrm{p}<0.001$ for LF, HF and LF/HF in both Sham and Load). Somewhat surprisingly there was an opposite effect in the control group with a significant decrease in HF and increase in the low frequency component and LF/HF ratio $(\mathrm{p}<0.001$ in each case) over the eight week period.

\section{Discussion}

The aim of the present study was to determine whether slow breathing training results in a modification of central neural pathways controlling blood pressure and the fact that slow breathing training reduced the pressor response to handgrip exercise clearly points to a central mechanism playing a major part. Adding an inspiratory load to the breathing training had no significant effect on either the reduction in resting blood pressure, or on the pressor response to hand grip, indicating that the slow breathing alone, rather than the contractile activity of the respiratory muscles, was key to the adaptations reported here.

The beneficial effects of breathing training for resting systolic blood pressure we report are very similar to previous reports where breathing has been regulated in various ways (Elliot et al. 2004, Schein et al. 2009, Viskoper et al. 2003). The values are also very similar to those we reported previously for the same subjects (Jones et al. 2010), except that the measurements for the present data were taken slightly later in the day. Probably for this reason the changes in diastolic pressure (Table 2) were just not significant, whereas there were significant changes in the early morning values reported previously (Jones et al. 2010). Although there was a trend for slightly larger changes in resting systolic pressure in the Loaded training group, there was no statistical difference between the No Load and Load groups. Both forms of breathing training reduced the pressor response to handgrip exercise despite the fact that the forearm 
muscles involved had not been trained.

The pre-training pressor response to forearm contractions (change in MAP $\sim 15 \quad \mathrm{~mm} \mathrm{Hg}$ ) was somewhat smaller than $\sim 25 \mathrm{~mm} \mathrm{Hg}$ reported by Delaney et al. (2010), but this may have been because the latter subjects had higher resting blood pressures since they had been off medication for two days prior to the experiment. The decrease in MAP pressor response with training was similar to the difference between pressor responses of normotensive and hypertensive subjects in the study of Delaney et al. (2010).

Blood pressure measurements are notoriously affected by a variety of emotional cues such as fear and anxiety as well as with the Valsalva maneuver sometimes used when trying to sustain a long muscle contraction. It is possible, therefore that the trained subjects may have been more relaxed or that there were subtle differences in breathholding during the second handgrip exercise. However, it is unlikely that this would account for the differences between the Control and Trained groups since both had the same experience of the hand grip test and none were observed breathholding during the test. Moreover, differences between the trained and control subjects were seen during the recovery phase of the handgrip exercise when they were resting and there was no reason why they should be breathing abnormally.

The pressor response to muscle contraction has a number of components, some being due to metabolic and mechanical reflexes arising in the working muscles, others being feed-forward from central command (Fisher and White 2004). The heart rate response to contraction is thought to be largely a consequence of central command since HR returns to baseline at the end of contraction even during post-exercise circulatory occlusion (PECO) and HR responses are also less pronounced if the muscle is activated by electrical stimulation rather than by voluntary effort (Fisher and White 1999). Systolic and diastolic blood pressures, on the other hand, remain elevated during PECO, indicating that the increased pressure during that phase is a consequence of metabolite accumulation in the muscle. There may also be a central component to the blood pressure rise since the PECO pressures are usually about half the level measured during contraction, but this could also reflect the afferent input from mechano-receptors active during the contraction but absent during PECO (Carrington et al. 2003).

The present results cannot differentiate between changes in central command or the central modification of metabo- or mechano-receptors as a result of breathing training; for this it would have been useful to have a period of PECO. What is clear, however, is that no matter whether the breathing training affected one, or all three, of the stimuli for pressor responses, the modification occurred at some central site rather than in the peripheral muscle.

The increased power in the high frequency region of the HRV spectrum is consistent with a modification of central control of cardiovascular function. The respiratory component of the spectrum evident in the HF region increases with decreasing breathing rate (down to 9 breaths per minute) and it is possible that the trained subjects altered their breathing pattern. However, Lehrer et al. (2006) found no change in breathing patterns after a period of biofeedback training which was similar in many ways to the slow breathing training used here.

It is not immediately clear how slow breathing training can effect a change in the central mechanisms regulating the pressor response but there have been reports that one of the acute effects of slow breathing is to increase the sensitivity of the baroreflex in patients with heart failure (Bernardi et al. 2001a) and hypertension (Joseph et al. 2005). Lehrer et al. (2006, 2003) also showed that HRV biofeedback, which is essentially slow breathing, not only increased baroreflex sensitivity during the slow breathing but also had more lasting effects as a result of 10 weeks of training. It is possible, therefore, that an increased sensitivity of the baroreflex as a result of training may more effectively buffer the increases in blood pressure in response to handgrip exercise. Slow breathing is associated with major changes in HRV and blood pressure variability (Lehrer et al. 2006, 2003) and these authors suggest that the large fluctuations may "exercise the baroreflex" which could lead to longer lasting modifications of function. It should be noted, however, that increased baroreflex sensitivity does not necessarily explain the reduction in resting blood pressure as a result of breathing training since this requires a change in the set point.

It has been observed that hypertensive subjects tend to have a low end-tidal $\mathrm{PCO}_{2}$ which may be a consequence of an increased sensitivity to $\mathrm{CO}_{2}$ (Joseph et al. 2005). It is possible that slow breathing might shift the balance of bicarbonate buffering in the blood by increasing end tidal- $\mathrm{PCO}_{2}$ with possible acute and long term effects. In future work it would be useful to determine how breathing rate, end tidal $\mathrm{PCO}_{2}$ and blood bicarbonate are affected by slow breathing training. 
Meditation, which generally involves slow breathing, is known to reduce levels of stress hormones (Brand et al. 2012, Fan et al. 2014) and it is possible that a change in circulating cortisol levels might affect central autonomic pathways, although it would be difficult to distinguish cause and effect.

In summary, we have shown for the first time that slow breathing training which reduces resting blood pressure also reduces the pressor response to handgrip exercise. The implication of these finding is that breathing training modifies central cardiovascular control which attenuates the pressor response to contraction of muscles throughout the body.

The fact that improvements in blood pressure control were seen with hypertensive patients who were considered to be well controlled with a variety of drugs highlights the fact that pharmacological treatments do not necessarily "cure" the problem and that slow breathing training, meditation or some form of exercise, is an important adjunct to even the best pharmacological treatments.

\section{Conflict of Interest}

There is no conflict of interest.

\section{Acknowledgements}

This study was supported by grants from the Thai Health Promotion Foundation, Ministry of Public Health, and the Graduate School and Faculty of Associated Medical Sciences, Khon Kaen University. The authors are grateful to the patients, nurses and officers of the Hypertension Clinic of Srinagarind Hospital for their assistance in the conduct of the study.

\section{References}

BERNARDI L, GABUTTI A, PORTA C, SPICUZZA L: Slow breathing reduces chemoreflex response to hypoxia and hypercapnia, and increases baroreflex sensitivity. J Hypertens 19: 2221-2229, 2001a.

BERNARDI L, SLEIGHT P, BANDINELLI G, CENCETTI S, FATTORINI L, WDOWCZYC-SZULC J, LAGI A: Effect of rosary prayer and yoga mantras on autonomic cardiovascular rhythms: comparative study. BMJ 323: 1446-1449, 2001b.

BRAND S, HOLSBOER-TRACHSLER E, NARANJO JR, SCHMIDT S: Influence of mindfulness practice on cortisol and sleep in long-term and short-term meditators. Neuropsychobiology 65: 109-118, 2012.

CARRINGTON CA, UBOLSAKKA C, WHITE MJ: Interaction between muscle metaboreflex and mechanoreflex modulation of arterial baroreflex sensitivity in exercise. J Appl Physiol 95: 43-48, 2003.

CHOBANIAN AV, BAKRIS GL, BLACK HR, CUSHMAN WC, GREEN LA, IZZO JL, JONES DW, MATERSON BJ, OPARIL S, WRIGHT JT, ROCCELLA EJ: The Seventh Report of the Joint National Committee on Prevention, Detection, Evaluation, and Treatment of High Blood Pressure: the JNC 7 report. JAMA 289: 2560-2572, 2003.

COOTE JH, HILTON SM, PEREZ-GONZALEZ JF: The reflex nature of the pressor response to muscular exercise. J Physiol 215: 789-804, 1971.

CYSARZ D, BÜSSING A: Cardiorespiratory synchronization during Zen meditation. Eur J Appl Physiol 95: 88-95, 2005.

DELANEY EP, GREANEY JL, EDWARDS DG, ROSE WC, FADEL PJ, FARQUHAR WB: Exaggerated sympathetic and pressor responses to handgrip exercise in older hypertensive humans: role of the muscle metaboreflex. $\mathrm{Am} \mathrm{J}$ Physiol Heart Circ Physiol 299: H1318-H1327, 2010.

DEVEREUX GR, WILES JD, SWAINE IL: Reductions in resting blood pressure after 4 weeks of isometric exercise training. Eur J Appl Physiol 109: 601-606, 2010.

ELLIOT WJ, IZZO JL, WHITE WB, ROSING DR, SNYDER CS, ALTER A, GAVISH B, BLACK HR: Graded blood pressure reduction in hypertensive outpatients associated with use of a device to assist with slow breathing. $J C l i n$ Hypertens 6: 553-559, 2004.

FAN Y, TANG YY, POSNER MI: Cortisol level modulated by integrative meditation in a dose-dependent fashion. Stress Health 30: 65-70, 2014.

FISHER JP, WHITE MJ: Muscle afferent contributions to the cardiovascular response to isometric exercise. Exp Physiol 89: 639-646, 2004.

FISHER WJ, WHITE MJ: Training-induced adaptations in the central command and peripheral reflex components of the pressor response to isometric exercise of the human triceps surae. J Physiol 520: 621-628, 1999. 
GROSSMAN E, GROSSMAN A, SCHEIN MH, ZIMLICHMAN R, GAVISH B: Breathing-control lowers blood pressure. J Hum Hypertens 15: 263-269, 2001.

HALBERT JA, SILAGY CA, FINUCANE P, WITHERS RT, HAMDORF PA, ANDREWS GR: The effectiveness of exercise training in lowering blood pressure: a meta-analysis of randomised controlled trials of 4 weeks or longer. J Hum Hypertens 11: 641-649, 1997.

HAMADA M, KAZATANI Y, SHIGEMATSU Y, ITO T, KOKUBU T, ISHISE S: Enhanced blood pressure response to isometric handgrip exercise in patients with essential hypertension: effects of propranolol and prazosin. J Hypertens 5: 305-309, 1987.

JONES CU, SANGTHONG B, PACHIRAT O: An inspiratory load enhances the antihypertensive effects of home-based training with slow deep breathing: a randomised trial. J Physiother 56: 179-186, 2010.

JOSEPH CN, PORTA C, CASUCCI G, CASIRAGHI N, MAFFEIS M, ROSSI M, BERNARDI L: Slow breathing improves arterial baroreflex sensitivity and decreases blood pressure in essential hypertension. Hypertension 46: 714-718, 2005.

LEHRER PM, VASCHILLO E, VASCHILLO B, LU SE, ECKBERG DL, EDELBERG R, SHIH WJ, LIN Y, KUUSELA TA, TAHVANAINEN KU, HAMER RM: Heart rate variability biofeedback increases baroreflex gain and peak expiratory flow. Psychosom Med 65: 796-805, 2003.

LEHRER P, VASCHILLO E, LU SE, ECKBERG D, VASCHILLO B, SCARDELLA A, HABIB R: Heart rate variability biofeedback: effects of age on heart rate variability, baroreflex gain, and asthma. Chest 129: 278-284, 2006.

O'SULLIVAN SE, BELL C: Training reduces autonomic cardiovascular responses to both exercise-dependent and -independent stimuli in humans. Auton Neurosci 91: 76-84, 2001.

PATEL C, NORTH WR: Randomised controlled trial of yoga and bio-feedback in management of hypertension. Lancet 2: 93-95, 1975.

RAY CA: Sympathetic adaptations to one-legged training. J Appl Physiol 86: 1583-1587, 1999.

RAY CA, CARRASCO DI: Isometric handgrip training reduces arterial pressure at rest without changes in sympathetic nerve activity. Am J Physiol Heart Circ Physiol 279: H245-H249, 2000.

ROSENTHAL T, ALTER A, PELEG E, GAVISH B: Device-guided breathing exercises reduce blood pressure: ambulatory and home measurements. Am J Hypertens 14: 74-76, 2001.

SAUSEN MT, DELANEY EP, STILLABOWER ME, FARQUHAR WB: Enhanced metaboreflex sensitivity in hypertensive humans. Eur J Appl Physiol 105: 351-356, 2009.

SCHEIN MH, GAVISH B, HERZ M, ROSNER-KAHANA D, NAVEH P, KNISHKOWY B, ZLOTNIKOV E, BEN-ZVI N, MELMED RN: Treating hypertension with a device that slows and regularises breathing: a randomised, double-blind controlled study. J Hum Hypertens 15: 271-278, 2001.

SCHEIN MH, GAVISH B, BAEVSKY T, KAUFMAN M, LEVINE S, NESSING A, ALTER A: Treating hypertension in type II diabetic patients with device-guided breathing: a randomized controlled trial. $J$ Hum Hypertens 23: 325$331,2009$.

SHARMA M, FRISHMAN WH, GANDHI K: RESPeRATE: nonpharmacological treatment of hypertension. Cardiol Rev 19: 47-51, 2011.

SPICUZZA L, GABUTTI A, PORTA C, MONTANO N, BERNARDI L: Yoga and chemoreflex response to hypoxia and hypercapnia. Lancet 356: 1495-1496, 2000.

SUMIMOTO T, HAMADA M, MUNETA S, SHIGEMATSU Y, FUJIWARA Y, SEKIYA M, KAZATANI Y, HIWADA K: Influence of age and severity of hypertension on blood pressure response to isometric handgrip exercise. J Hum Hypertens 5: 399-403, 1991.

TAYLOR AC, MCCARTNEY N, KAMATH MV, WILEY RL: Isometric training lowers resting blood pressure and modulates autonomic control. Med Sci Sports Exerc 35: 251-256, 2003.

VISKOPER R, SHAPIRA I, PRILUCK R, MINDLIN R, CHORNIA L, LASZT A, DICKER D, GAVISH B, ALTER A: Nonpharmacologic treatment of resistant hypertensives by device-guided slow breathing exercises. $\mathrm{Am} J$ Hypertens 16: 484-487, 2003.

WHELTON SP, CHIN A, XIN X, HE J: Effect of aerobic exercise on blood pressure: a meta-analysis of randomized, controlled trials. Ann Intern Med 136: 493-503, 2002. 